\title{
REFLEXÕES SOBRE OS CONCEITOS DE ADOLESCÊNCIA E JUVENTUDE: UMA REVISÃO INTEGRATIVA
}

\author{
REFLECTIONS ON THE CONCEPTS OF ADOLESCENCE AND YOUTH: AN INTEGRATIVE \\ REVIEW
}

REFLEXIONES SOBRE LOS CONCEPTOS DE ADOLESCENCIA Y JUVENTUD: UNA REVISIÓN INTEGRATIVA

\section{Larissa Horácio Barbosa- \\ Silva \\ (iD) 9 \\ Especialista em Educação \\ Especial/Inclusiva \\ Psicóloga do Instituto Federal do \\ Maranhão (IFMA) \\ Discente do Programa de Pós- \\ Graduação em Educação \\ Profissional e Tecnológica \\ larissa.barbosa@ifma.edu.br}

\section{Álvaro Itaúna Schalcher Pereira \\ iD 9}

Doutor em Engenharia e Ciência de Alimentos

Professor do Instituto Federal do

Maranhão (IFMA)

Docente do Programa de Pós-

Graduação em Educação

Profissional e Tecnológica (IFMA)

alvaro.pereira@ifma.edu.br

\section{Francisco Adelton Alves}

Ribeiro

(iD) 9

Doutor em Biotecnologia

Professor do Instituto Federal do

Maranhão (IFMA)

Docente do Programa de Pós-

Graduação em Educação

Profissional e Tecnológica (IFMA)

adelton@ifma.edu.br

\begin{abstract}
Resumo
Os conceitos de adolescência e juventude nem sempre existiram, mas foram construídos ao longo da história da humanidade. É relevante discutir essas definições e pensar no que consistem a adolescência e a juventude a fim de que se possa apontar caminhos para a construção de práticas significativas para esses públicos. A partir da questão norteadora "Como a literatura no âmbito das Ciências Sociais, Humanidades e Psicologia, de modo particular, conceitua a adolescência e a juventude?". O presente estudo se caracteriza como uma revisão de literatura do tipo integrativa - que consiste numa síntese de ideias e conceitos a partir de etapas bem definidas de seleção e avaliação de estudos -, com o objetivo de analisar como os conceitos de adolescência e juventude têm sido discutidos nos referidos campos da literatura acadêmica. Foi possível encontrar uma predominância de artigos baseados na perspectiva sócio-histórica e na psicanálise, que, embora divirjam em alguns aspectos, apontam para a necessidade de um distanciamento de visões puramente desenvolvimentistas e naturalizantes. Conclui-se que para a construção de práticas significativas junto aos adolescentes e jovens, faz-se necessário um olhar contextualizado, sem encerrar uma identidade preestabelecida, trazendo as multiplicidades de cada sujeito.
\end{abstract}

Palavras-chave: Perspectiva sócio-histórica. Psicanálise. Práticas significativas.

Recebido em: 2 de março de 2021.

Aprovado em: 27 de abril de 2021.

Como citar esse artigo (ABNT):

BARBOSA-SILVA, Larissa Horácio; PEREIRA, Álvaro Itaúna Schalcher; RIBEIRO, Francisco Adelton Alves. Reflexões sobre os conceitos de adolescência e juventude: uma revisão integrativa. Revista Prática Docente, v. 6, n. 1, e026, 2021. http://doi.org/10.23926/RPD.2021.v6.n1.e026.id1045 


\begin{abstract}
The concepts of adolescence and youth did not always exist, but were built throughout human history. It is relevant to discuss these definitions and thinking about what adolescence and youth consist, in order to point out ways to build meaningful practices for these audiences. From the guiding question "How does literature in the field of Social Sciences, Humanities and Psychology, in particular, conceptualize adolescence and youth?", the present study is characterized as an integrative literature review - which consists of a synthesis of ideas and concepts from well-defined stages of study selection and evaluation -, with the aim of analyze how the concepts of adolescence and youth have been discussed in the referred fields of academic literature. It was possible to find a predominance of articles based on the social-historical perspective and psychoanalysis, who, although they differ in some respects, point to the need to move away from the purely developmental and naturalizing views. It is concluded that for the construction of meaningful practices for adolescents and young people, it is necessary to have a contextualized look, without ending a predetermined identity, bringing the multiplicities of each subject.
\end{abstract}

Keywords: Social-historical perspective. Psychoanalysis. Meaningful practices.

\title{
Resumen
}

Los conceptos de adolescencia y juventud no siempre existieron, pero fueron construidos a lo largo de la historia humana. Es relevante discutir estas definiciones y pensar en qué consisten la adolescencia y la juventud con el fin de señalar formas de construir prácticas significativas para estas audiencias. Basado en la pregunta orientadora "¿Cómo conceptualiza la literatura en el campo de las Ciencias Sociales, Humanidades y Psicología, en particular, la adolescencia y la juventud?", el presente estudio se caracteriza por ser una revisión integrativa de la literatura - que consiste en una síntesis de ideas y conceptos de etapas bien definidas de selección y evaluación de estudios -, con el fin de analizar cómo se han discutido los conceptos de adolescencia y juventud en los referidos campos de la literatura académica. Se pudo encontrar un predominio de artículos basados en la perspectiva sociohistórica y el psicoanálisis, que, aunque difieren en algunos aspectos, apuntan a la necesidad de distanciarse de puntos de vista puramente desarrollistas y naturalizadores. Concluimos que para la construcción de prácticas significativas con adolescentes y jóvenes, es necesario tener un mirar contextualizado, sin acabar con una identidad preestabelecida, trayendo las multiplicidades presientes en cada sujeto.

Palabras clave: Perspectiva sociohistórica. Psicanálisis. Prácticas significativas. 


\section{INTRODUÇÃo}

Ao considerar a adolescência e a juventude, cabe mencionar que esses não são conceitos que sempre existiram, mas que foram construídos ao longo da história da humanidade. Pensar em como os mesmos são vistos na literatura acadêmica, como são concebidos pelos estudos que as colocam em pauta, faz-se necessário para uma reflexão sobre como os estudos se direcionam a esse público e quais as implicações e discussões advindas do modo de percebêlos.

Segundo Shoen-Ferreira, Aznar-Farias e Silvares (2010), somente nos séculos XIX e $\mathrm{XX}$, um conjunto de acontecimentos sociais, culturais e demográficos permitiram o estabelecimento da adolescência como período singular do desenvolvimento humano, distinto da infância e da vida adulta. Bock (2007, p. 68), por sua vez, situa a adolescência e a juventude como resultado de mudanças socioeconômicas, percebendo-as como um "período de latência social constituída a partir da sociedade capitalista gerada por questões de ingresso no mercado de trabalho e extensão do período escolar, da necessidade do preparo técnico".

Sendo uma construção, a adolescência e a juventude não são algo dado, senão imerso em transformações ao longo deste espaço de tempo. Por isso, discutir a adolescência e a juventude a partir da literatura acadêmica brasileira se faz necessário para que se perceba como se colocam as teorizações a esse respeito e como isso pode se refletir nas mais diversas práticas que tenham os adolescentes e jovens como público-alvo, como na atuação dos profissionais no contexto escolar e nas políticas públicas de modo geral, visto que o modo como se concebe determinada categoria pode trazer implicações nas ações a ela dirigidas pelos profissionais.

O interesse pelo tema surgiu a partir dos estudos da primeira autora deste artigo para a produção de sua dissertação que traz como tema o serviço dos psicólogos junto ao público do Ensino Médio Integrado, que é constituído por discentes de 14 a 19 anos, no Instituto Federal de Educação, Ciência e Tecnologia do Maranhão (IFMA). Surge a seguinte questão de pesquisa: como a literatura no âmbito das Ciências Sociais, Humanidades e Psicologia, de modo particular, conceitua a adolescência e a juventude?

Neste sentido, a presente pesquisa objetivou analisar como os conceitos de adolescência e juventude têm sido discutidos nos referidos campos da literatura acadêmica. Para tanto, foi realizada uma revisão de literatura do tipo integrativa - que consiste numa síntese de diversos estudos e conceitos a partir de etapas definidas de seleção e avaliação de estudos - sobre artigos que discutem a temática, de modo a observar não só as definições dos termos, mas em quais 
teorias os autores se debruçam sobre esse aspecto conceitual e quais encontros e desencontros podem-se extrair dessa apreciação.

\title{
2 ConteXtualizando A Questão
}

Conforme a legislação brasileira para o Estatuto da Juventude, jovens são aqueles com idade entre 15 e 29 anos (BRASIL, 2013) e para o Estatuto da Criança e do Adolescente (ECA) considera-se adolescente a pessoa entre 12 e 18 anos (BRASIL, 1990). Há, portanto, uma faixa etária comum para as duas denominações.

Freitas, Abramo e León (2005, p. 7), ao discutirem o uso dos termos adolescência e juventude no Brasil, destacam que:

\begin{abstract}
Normalmente, quando psicólogos vão descrever ou fazer referências aos processos que marcam esta fase da vida (a puberdade, as oscilações emocionais, as características comportamentais que são desencadeadas pelas mudanças de status etc.) usam o termo adolescência. Quando sociólogos, demógrafos e historiadores se referem à categoria social, como segmento da população, como geração no contexto histórico, ou como atores no espaço público, o termo mais usado é juventude.
\end{abstract}

Ainda conforme Freitas, Abramo e León (2005), entre os anos 1980 e meados de 1990, a adolescência ganhou destaque em decorrência da luta por direitos e proteção para crianças e adolescentes, que culminou com o ECA. Isso teria deixado fora da temática social aqueles com mais de 18 anos, que voltaram à cena a partir das preocupações surgidas em relação à inserção social, à crise no mundo do trabalho e ao aumento da violência. No que tange às políticas públicas, consideram que a tendência é a divisão em:

(...) Dois momentos do período de vida amplamente denominado juventude, sendo que a adolescência corresponde à primeira fase (tomando como referência a faixa etária que vai dos 12 aos 17 anos, como estabelecido pelo ECA), caracterizada principalmente pelas mudanças específicas que marcam essa fase como um período específico de desenvolvimento, de preparação para uma inserção futura; e juventude (ao que alguns agregam o qualificativo propriamente dito, ou então denominam como jovens adultos, ou ainda pós adolescência) para se referir à fase posterior, de construção de trajetórias de entrada na vida social (FREITAS; ABRAMO; LEÓN, 2005, p. 8).

Cabe citar, no entanto, que nem sempre a diferenciação dos conceitos de adolescência e juventude aparece de forma clara. Bock (2007), ao destacar as mudanças na sociedade em relação ao papel do Estado e das transformações econômicas na construção da adolescência e da juventude, não diferencia os dois conceitos. Conforme a referida autora, ao passo que surgem a diversificação do trabalho e a maior necessidade de qualificação para desenvolvê-lo, o jovem passa a permanecer mais tempo sob a tutela familiar. 
Segundo Bock (2007, p. 68):

A ciência, por outro lado, resolveu muitos problemas do homem e ele teve a sua vida prolongada, o que trouxe desafios para a sociedade, em termos de mercado de trabalho e formas de sobrevivência. Estavam dadas as condições para que se mantivesse a criança mais tempo sob a tutela dos pais, sem ingressar no mercado de trabalho. Mantê-las na escola foi a solução. A extensão do período escolar e o consequente distanciamento dos pais e da família e a aproximação de um grupo de iguais foram consequências destas exigências sociais. A sociedade então assiste à criação de um novo grupo social com padrão coletivo de comportamento - a juventude/a adolescência.

Nota-se que a discussão em torno da adolescência e da juventude é ampla e construída a partir de bases epistemológicas diferentes, o que traz modos diversos de conceituá-las e percebê-las. Pensando-as como fenômenos que atravessam muito mais do que a idade, serão apresentadas, a seguir, algumas definições quanto às duas denominações:

\subsection{SOBRE A ADOLESCÊNCIA}

Segundo Shoen-Ferreira, Aznar-Farias e Silvares (2010), apesar das transformações biológicas da puberdade serem universais, isso não é suficiente para constituir a adolescência, que traz muitas outras questões menos visíveis e mais diversificadas.

O conceito de adolescência como existe no mundo moderno nem sempre existiu. Conforme, Ariès (1981), em seu estudo sobre a história da criança e da família, na sociedade francesa, até o século XVIII, a adolescência foi confundida com a infância, não havia lugar para a adolescência. $\mathrm{O}$ autor se refere à indiferença quanto aos fatores biológicos; não se limitaria a infância pela puberdade porque a ideia de infância estava ligada à dependência, só se saía da infância ao superar ou, pelo menos, diminuir a dependência da família.

Ao longo do tempo os modos de viver se alteram, concepções que hoje são utilizadas nem sempre existiram ou foram vistas da mesma forma. Quando se fala naquilo que é próprio do ser humano, não há nada mais inerente do que a capacidade de transformar e ser transformado pelo que está ao seu redor. Sendo assim, a noção sobre a adolescência não poderia ser sempre a mesma.

Numa perspectiva sócio-histórica, Naves (2016) define a adolescência como um fenômeno complexo a ser observado em sua totalidade e destaca que:

A adolescência concebida como consequência inevitável do desenvolvimento, como período de passagem obrigatório para a vida adulta, sinalizada pelo aparecimento de marcas corporais e significada como uma fase problemática da vida, coloca o adolescente em situação de desvalorização social em relação ao mundo adulto (NAVES, 2016, p. 34). 
Para Naves (2016), portanto, conceber a adolescência somente como uma fase natural a ser suplantada pela chegada da idade adulta traz uma desconsideração quanto à riqueza da vivência desses sujeitos, fazendo-se necessária uma visão crítica e um olhar atento para os adolescentes nos mais diversos contextos.

Neste sentido, Matheus (2004), em estudo onde reflete sobre as várias visões de autores pautados na Psicanálise, percebe o conceito de adolescência como algo ainda claudicante, ora visto como fenômeno social, ora como momento necessário à constituição do sujeito. $\mathrm{O}$ autor coloca que o próprio conceito na perspectiva psicanalítica produz incômodo e questiona o que está estabelecido. O que permite perceber que ainda há muito a ser discutido.

\subsection{SOBRE A JUVENTUDE}

Ao falar sobre a juventude, Dayrell (2003) afirma que se deve compreendê-la não como uma etapa com um fim determinado ou simples preparação para a vida adulta, mas defende um modo próprio de ser dos jovens, que se constrói na sua cotidianidade. O referido autor ressalta que "a juventude constitui um momento determinado, mas não se reduz a uma passagem; ela assume uma importância em si mesma" (DAYRELL, 2003, p. 42).

Conforme o pensamento de Dayrell (2003), seria limitado olhar para a juventude apenas como algo passageiro, sem reconhecer sua singularidade. O referido autor a percebe como uma parte do processo de constituição dos sujeitos. Fala em juventudes, no plural, de modo que se possa destacar a diversidade desses modos de ser, que possuem como base o meio social.

Conforme Pais (1990, p. 150), “a juventude pode ser tomada tanto como uma unidade (quando referida a uma fase da vida), como ser tomada no sentido de conjunto social obviamente diversificado". Embora, seja possível estabelecer uma faixa etária como referente à juventude, cabe ressaltar que há uma diversidade de situações sociais que farão esse grupo essencialmente heterogêneo. Pais (1990) coloca que uma forma de melhor abordar os estudos sobre a juventude é olhar a sociedade através do cotidiano, das vivências dos jovens.

Peralva (1997, p. 15) recorda que "as idades da vida, embora ancoradas no desenvolvimento biopsíquico dos indivíduos, não são fenômeno puramente natural, mas social e histórico, datado, portanto, e inseparável do lento processo de constituição da modernidade". Ou seja, todo o processo de desenvolvimento humano precisa ser visto a partir do contexto de cada época. Com o aumento da expectativa de vida, por exemplo, para Peralva (1997, p. 23), "o envelhecimento postergado transforma o jovem, de promessa de futuro que era, em modelo cultural do presente", associando a juventude a um estilo de vida, não mais a um grupo etário. 
Há várias formas de caracterizar a juventude, porém, é possível notar, que a diversidade e o contexto social em que os jovens estão inseridos são fatores preponderantes para que os estudos que se pautem nesse público se aproximem das suas realidades.

$\mathrm{Na}$ presente pesquisa não se pretende esgotar a discussão sobre os conceitos de adolescência e juventude, mas trazer um panorama do que se tem produzido na literatura recente quanto a essas denominações. Para tanto, a seguir está descrito o método utilizado, bem como os resultados e as inferências deles advindas.

\section{CAMINHO PERCORRIDO PELA PESQUISA}

A presente pesquisa caracteriza-se como uma revisão de literatura do tipo integrativa, que, conforme Botelho, Cunha e Macedo (2011), constitui-se como um método que procura “traçar uma análise sobre o conhecimento já construído em pesquisas anteriores sobre um determinado tema, (...) possibilita a síntese de vários estudos já publicados, permitindo a geração de novos conhecimentos (...). O termo 'integrativa' tem origem na integração de opiniões, conceitos ou ideias provenientes das pesquisas utilizadas no método" (BOTELHO, CUNHA, MACEDO, 2011, p. 127).

De acordo com Rother (2007), os artigos de revisão podem ser divididos em dois grandes grupos: revisões narrativas e revisões sistemáticas. As revisões narrativas constituirse-iam como uma "análise da literatura publicada em livros, artigos de revista impressas e/ou eletrônicas na interpretação e análise crítica pessoal do autor (ROTHER, 2007, s/p.)”, sem uma preocupação em descrever a metodologia utilizada para a busca das referências ou os critérios de avaliação para a seleção dos trabalhos. Já as revisões sistemáticas partiriam de métodos explícitos e sistemáticos de avaliação e seleção de estudos (ROTHER, 2007).

Botelho, Cunha e Macedo (2011) situam a revisão integrativa como um dos tipos de revisão sistemática, que tem como principal característica a composição de etapas bem definidas que se constituem da seguinte forma: 1) identificação do tema e pergunta de pesquisa; 2) critérios de inclusão e exclusão; 3) identificação dos estudos; 4) categorização dos estudos; 5) análise e interpretação dos resultados. Possibilita revisar métodos, teorias e estudos sobre determinado tópico, pode ser qualitativa ou quantitativa e descreve as etapas metodológicas utilizadas na busca e análise dos estudos utilizados.

A partir da pergunta central "Como a literatura no âmbito das Ciências Sociais, Humanidades e Psicologia, de modo particular, conceitua a adolescência e a juventude?", foram selecionadas as bases de dados IndexPsi e Web of Science, onde realizou-se uma busca a partir 
dos descritores 'adolescência e conceito', 'adolescente e conceito', 'juventude e conceito', referentes ao intervalo de 2005 a 2020. Optou-se por um intervalo de tempo extenso devido à possibilidade de não haverem muitas produções, mas também em decorrência de 2005 ser um ano importante para a juventude no Brasil com a promulgação da Lei 11.129/2005, que instituiu o Programa Nacional de Inclusão de Jovens (ProJovem), criou o Conselho Nacional da Juventude (CNJ) e a Secretaria Nacional de Juventude, o que poderia ser um fator de propulsão para produções acadêmicas sobre o tema, embora essa hipótese não tenha se confirmado ao longo da pesquisa.

Como critérios de inclusão foram selecionados os artigos que versassem sobre o conceito de adolescência ou juventude, disponibilizados de forma completa e em português. Como critérios de exclusão, foram descartados artigos que não tratassem da temática disposta, embora apresentassem os descritores e aqueles que incluíssem outras categorias em suas discussões além da adolescência e da juventude.

Atendendo aos critérios de inclusão, inicialmente foram encontrados 36 artigos na base de dados IndexPsi e 113 na Web of Science. Após leitura dos títulos e resumos, foram feitas as exclusões conforme os critérios citados, assim como das repetições. Dessa forma, após as exclusões necessárias, chegou-se ao total de 12 artigos que serão expostos e discutidos a seguir.

\section{Resultados E Discussão}

Para melhor apresentação dos dados coletados, optou-se por uma breve contextualização de cada um dos 12 artigos encontrados, apresentados em ordem cronológica, focando na questão de pesquisa estabelecida, de modo que, para cada um dos estudos, procurou-se utilizar a denominação de adolescência ou juventude conforme utilizada pelos autores de cada artigo. Posteriormente, são descritos alguns encontros e diferenças percebidos entre as produções e outros apontamentos.

\subsection{CONCEITUAÇÕES DE ADOLESCÊNCIA E JUVENTUDE}

Coimbra, Bocco e Nascimento (2005) trazem uma discussão a respeito do termo adolescência e suas implicações na atualidade. Atentam para o uso indiscriminado e naturalizante do termo, sem percebê-la como uma questão cultural e construída ao longo da história. Conforme as referidas autoras, há uma visão desenvolvimentista, segundo a qual todos deveriam passar pela adolescência e de modo similar, de forma que algumas "características passam a ser percebidas como uma essência, em que 'qualidades' e 'defeitos' como rebeldia, 
desinteresse, crise, instabilidade afetiva, descontentamento, melancolia, agressividade, impulsividade, entusiasmo, timidez e introspecção passam a ser sinônimos do ser adolescente, constituindo uma 'identidade adolescente"” (COIMBRA; BOCCO; NASCIMENTO, 2005, p. 5).

Dessa forma, Coimbra, Bocco e Nascimento (2005) apontam que a visão homogênea traz limitações, como se houvesse um jeito certo de ser adolescente, negando a diversidade, as construções sociais. Algo ressaltado pelas autoras é a lógica capitalista em torno dessa visão homogeneizante da adolescência, havendo todo um comércio que sobrevive à custa da adolescência, com roupas, músicas e alimentos voltados a esse público. Se, por um lado, o modo de produção capitalista traz uma visão universal e homogênea da adolescência, por outro, a "lógica individualista e culpabilizante da subjetivação capitalística vai dizer que o modo como cada um enfrenta e resolve tal fase será determinado pelo próprio indivíduo e por sua capacidade, ou falta dela" (COIMBRA; BOCCO; NASCIMENTO, 2005, p. 6).

Por fim, Coimbra, Bocco e Nascimento (2005) propõem a subversão do termo adolescência pelo conceito de juventude, que consideram mais apropriado por abrir espaço às multiplicidades próprias do ser humano, sem o fechamento de uma identidade adolescente, de modo que se possa perceber o adolescente como sujeito que possui várias nuances em seu modo de ser.

Augusto (2005) faz uma análise sobre o legado intelectual de Marialice Foracchi e a sociologia da juventude. Nesse contexto, a juventude é caracterizada como uma fase da vida, que possui força social renovadora e estilo próprio de existência, está além de uma fase cronológica. Considera-se também importante para a sua construção os recursos disponíveis, as alternativas de inserção social e os caminhos oferecidos em sua trajetória.

Em sua análise, Augusto (2005), apresenta questionamentos sobre as maneiras de ser impostas à juventude, visto que não há uma unidade da juventude no que tange às diferenças socioeconômicas e que estas terão grande peso na constituição dos jovens, portanto, haverá diversas formas de ser. Aponta também características que são julgadas de forma ambivalente, por exemplo, ao mesmo tempo em que é visto como audacioso, o jovem é inexperiente, impulsivo (tendo essa característica como algo positivo), mas indeciso. As características juvenis referem-se principalmente à capacidade de vivenciar o novo. Augusto (2005) questiona a hierarquização das fases da vida, onde o adulto é colocado como superior, muitas vezes aparecendo a vida adulta como uma etapa de rigidez, onde não há lugar para improvisação e 
inovação. Num mundo regido pelas mudanças, isso a colocaria em desvantagem em relação à juventude, não em situação de superioridade.

Traverso-Yépez e Pinheiro (2005) discutem o conceito de adolescência pela questão social e de gênero. Em pesquisa realizada com adolescentes de um bairro de baixa renda, trazem as diferenças de oportunidades entre adolescentes em condições sociais diferentes e, dentre aqueles com condições semelhantes, o peso das questões de gênero, demonstrando que não há uma só adolescência, mas múltiplas perspectivas condicionadas pelo meio social.

Traverso-Yépez e Pinheiro (2005) buscam dar voz aos participantes da pesquisa, relatando suas visões sobre a adolescência. De modo geral, os rapazes percebem esse momento de suas vidas de forma mais positiva, as moças percebem um crescimento das responsabilidades, sobretudo domésticas, e uma diminuição da liberdade. Outra questão é a violência, vivenciada na rua pelos meninos e dentro de casa pelas meninas. Quanto às perspectivas, as meninas planejam mais, porém, nem sempre conseguem colocar em prática seus planos, geralmente em decorrência da chegada de filhos. Concluem destacando o peso das questões de gênero e naturalização dos estereótipos sexistas na vivência dos adolescentes entrevistados, não havendo, por exemplo, um questionamento das meninas quanto à necessidade de permanecer e cuidar da casa.

Bertol e Souza (2010) problematizam a atribuição da rebeldia e da transgressão como inerentes à adolescência. Rejeitam a visão desenvolvimentista segundo a qual a adolescência existiria como fase da vida universal e generalizada. Destacam que, se essa ideia naturalizante da adolescência é mantida, dificulta a possibilidade de o sujeito se expressar em sua singularidade e ser percebido como tal, correndo-se o risco de procurar encaixá-lo em padrões de normalidade e anormalidade, que muitas vezes levam a uma lógica de patologização.

Para Bertol e Souza (2010, p. 836), a atribuição de rebeldia à adolescência advém da ideia de que nessa fase seria "possível a satisfação dos desejos, deixando de lado os deveres e as obrigações que constrangem os adultos" e da leitura desenvolvimentista que considera o adolescente como aquele que não desenvolveu toda sua capacidade cognitiva e, por isso, estaria mais propenso a transgredir as leis sociais, "sendo necessário reprimi-lo para melhor submetêlo a essas leis" (BERTOL; SOUZA, 2010, p. 837).

Bertol e Souza (2010) entendem que considerar a transgressão como algo natural da adolescência traz uma desresponsabilização dos adolescentes, por serem vistos como imaturos, ao mesmo tempo em que exige-se uma punição para seus atos, como nas discussões sobre a 
redução da maioridade penal. Isso acaba por gerar violência, ao passo que a agressividade e a punição passam a ser vistas como necessárias no disciplinamento dos adolescentes, enquanto as discussões sobre os conflitos advindos de sua relação com o mundo ficam esquecidas.

Maheirie et al. (2013) analisam o conceito de juventude e política na produção acadêmica no período de 2002 a 2011, a partir de 33 artigos. Os autores agregam os estudos em 5 categorias quanto ao conceito de juventude: 1) estudos que veem a juventude como momento propício para a formação e inserção na política; 2) existência de uma subjetividade juvenil comum, apesar dos diferentes estratos sociais; 3) compreensão crítica da juventude, como condição social e historicamente produzida; 4) jovens e formas de participação política, que discutem o envolvimento e militância em ações coletivas; e 5) artigos que não problematizam o conceito de jovem ou juventude, definindo-os a partir de uma faixa etária e/ou momento de vida.

Quanto à definição de política, definem 4 categorias: 1) estudos que colocam a política como campo de lutas e tensões; 2) estudos que enfatizam relações de poder, destacando gênero, raça, classe social e sexualidade; 3) política como campo ideológico institucionalizado; e 4) política como dimensão do vivido, não problematizada.

Andrade e Meyer (2014) trazem uma pesquisa de campo, realizada com jovens da Educação de Jovens e Adultos de uma escola de periferia, com o objetivo de discutir relações entre moratória social, juventude e gênero. As referidas autoras compreendem a juventude como uma condição histórico-cultural, que deve ser analisada em suas diferentes dimensões, não se trata de algo dado ou fixo.

Um dado interessante destacado nas falas é a visão da escola como importante espaço de delimitação da experiência da juventude, local de pertencimento, reprodução e atualização de discursos. Quanto à questão da moratória social, que seria o tempo maior de permanência dos jovens com sua família de origem, Andrade e Meyer (2014) apontam que essa vivência, embora atribuída por outros estudos apenas à classe média, também ocorre nas populações de baixa renda "como adiamento, suspensão e/ou reinserção em 'contextos adultos"” (ANDRADE; MEYER, 2014, p. 92). Um exemplo disso são os discursos dos entrevistados onde aparece o pensamento de que sair da juventude, ou seja, adentrar a vida adulta, traz um período de maior responsabilidade, como constituir uma família e sustentar-se a partir do próprio trabalho, não atrelando essas ideias a fatores de idade. Alguns deles veem-se como jovens por ainda estarem 
na escola, outros caracterizam a juventude a partir de ideais de alegria e boa disposição, outros pelo fato de não ter as responsabilidades da vida adulta.

No que se refere ao gênero, nota-se a visão da mulher como responsável pelo ambiente doméstico e cuidados gerais com a casa e a família, não havendo questionamentos a esse respeito. Nesse sentido, algumas das jovens entrevistadas veem essa responsabilidade como algo da vida adulta, preferindo adiar essa fase em suas vidas.

Teixeira (2014) traz um relato de experiência em que realizou uma intervenção psicanalítica em um caso de ato infracional cometido por uma adolescente, que foi surpreendida pela polícia ao cometer furtos. Como era proveniente de uma família com boas condições financeiras, a adolescente foi encaminhada para terapia em consultório particular como condição para que não cumprisse medidas socioeducativas, que, conforme a família, trariam muita exposição.

Teixeira (2014) concebe a adolescência de forma não naturalizada, mas histórica, percebendo o adolescente como um sujeito de passagem que, em sua saída da infância será cobrado em relação ao lugar que ocupa nas relações familiares, em suas aspirações quanto ao trabalho e da relação com seus pares. Questiona a expressão "adolescente em conflito com a lei”, demonstrando que há um lugar de exclusão, mesmo que a intervenção busque a inclusão social, como se o sujeito estivesse colado a esse rótulo. Não se trata de não promover a responsabilização, ao contrário, há a necessidade de incluí-lo na lei e nas normas às quais todos estão submetidos, visto que se constituem como condição para a construção da cidadania e da autonomia. No caso da adolescente atendida, entendeu-se que a melhor forma de incluí-la seria cumprir as medidas socioeducativas, procurando não excluí-la do espaço social regido pelas leis.

Trancoso e Oliveira (2014) realizam uma metassíntese procurando descrever e discutir o estado do conhecimento da produção acadêmica no Brasil, entre os anos de 2007 e 2011 sobre o conceito de juventude. Para tanto, analisam artigos, dissertações e teses encontrados no Scielo, a partir do Google Acadêmico, e no site da Coordenação de Aperfeiçoamento de Pessoal de Nível Superior (CAPES).

Trancoso e Oliveira (2014) dividem as produções acadêmicas encontradas em cinco grupos a partir dos conceitos de juventude que nelas aparecem: 1) um conceito em movimento, que considera a importância da construção sociocultural, mas que precisa ser definido de forma rigorosa, tendo em vista a produção acadêmica e o desenvolvimento de políticas públicas; 2) 
algo distinto da adolescência, vista como o momento em que a pessoa inicia seu envolvimento nas questões sociais e políticas e se encaminha para a vida adulta; 3) período de transição entre infância e fase adulta, com características próprias que devem ser consideradas pela sociedade; 4) jeito de estar no mundo, que está ao alcance de todos, devido a valores atribuídos ao que é ser jovem; 5) posturas intrínsecas do ser jovem, tais como questionar a ordem social vigente e produzir mudanças, porém, considera-se que há uma construção social e que cada tempo produz os seus jovens.

Algo destacado por Trancoso e Oliveira (2014) é a heterogeneidade de conceitos de juventude, suas múltiplas construções e visões teóricas. Destacam a importância de pensar o conceito e o fato de grande parte das produções trazerem a discussão acerca da visão histórica da juventude, não percebendo-a como algo estático, e como essa reflexão se faz cada vez mais indispensável a fim de questionar o modo de produção vigente, com suas exclusões socioeconômicas e questões de poder.

Oliveira e Machado (2015), ao falarem sobre adolescência e espetacularização da vida, refletem, sob uma perspectiva psicanalítica, sobre a adolescência vivida em torno de um espetáculo das mídias, de modo que o processo de constituição do sujeito, sua formação como pessoa, já não ocorreria intermediada por relações concretas, ou seja, a partir da identificação com seus semelhantes, com as pessoas com quem convive, mas por meio de representações midiáticas, como telenovelas ou filmes. Os autores concebem a adolescência como uma fase de sofrimentos inevitáveis, tais como o luto $^{1}$ pela perda do corpo infantil e dos pais da infância para assumir um corpo sexualizado e uma percepção diferente acerca dos pais.

Oliveira e Machado (2015) destacam, ainda, a solidão afetiva que marca a vida de muitos adolescentes que crescem sob a supervisão de cuidadores pagos, ao lado de videogames, computadores e televisões. Há um distanciamento das obras de arte e pensamento, de modo que já não há espaço para refletir sobre si mesmo, o que acarreta um consumo acrítico dos conteúdos midiáticos, fazendo com que a adolescência se torne "cada vez mais isolada das possibilidades de construção de uma cultura própria através da qual pudessem mostrar suas demandas sociais

\footnotetext{
${ }^{1}$ Aberastury e Knobel (1981) trazem uma teoria onde a adolescência seria um momento caracterizado pela elaboração de três lutos fundamentais: a) luto pelo corpo infantil, onde se depara com as mudanças biológicas e com o sentimento de impotência diante dessas modificações, perde-se o corpo infantil "com uma mente ainda na infância e com um corpo que vai se tornando adulto" (ABERASTURY; KNOBEL, 1981, p. 81); b) luto pela identidade e pelo papel infantil, em que ocorreria uma confusão de papéis, visto que não se pode manter a dependência infantil, ao mesmo tempo em que não pode assumir a independência adulta; c) luto pelos pais da infância, onde a relação infantil com os pais vai sendo abandonada, algo que ocorre de ambos os lados, visto que os pais também precisarão aprender a lidar com as mudanças ocorridas com os filhos.
} 
e anseios existenciais" (OLIVEIRA; MACHADO, 2015, p. 534). Os mesmos autores alertam para a fragilização da historicidade e da memória, próprias da humanidade, num momento em que celebridades e publicidade assumem mais valor do que os sujeitos concretos.

Gurski e Pereira (2016) realizam uma discussão psicanalítica sobre a adolescência e sua experiência com o tempo. Conceituam a adolescência como uma operação psíquica, de forma que não se trata de uma condição física, hormonal, mas uma construção social e psíquica: “o processo adolescente revela, tanto a insuficiência dos referenciais infantis quanto a dose de urgência que o imperativo da inscrição social toma na passagem para a adolescência" (GURSKY; PEREIRA, 2016, p. 435).

Gurski e Pereira (2016) falam sobre a supervalorização da juventude como algo a ser buscado por todos, como sinônimo de sucesso e gozo pleno, não há mais a valorização do envelhecimento, da experiência acumulada. Isso acarreta no jovem uma sensação de desamparo, devido ao excesso de presente e à falta de alteridade geracional, visto que todos procuram ser jovens. O prazer transforma-se em um dever, gerando mal-estar, já que o gozo pleno é impossível. Por fim, Gurski e Pereira (2016) apontam que muitas das questões encontradas nas clínicas e vistas como adoecimentos psíquicos, bem como a extensão da adolescência pode ser uma forma de lidar com a ausência da experiência, fazendo com que haja um aumento desse "tempo de compreender", como o denominam os autores, a fim de que possam se constituírem como sujeitos.

Lopes e Carvalho (2017) realizam um estudo com jovens de um assentamento rural organizado pelo Movimento dos Trabalhadores Rurais Sem-Terra, com o objetivo de analisar a construção da identidade vinculada à terra. Os autores consideram a juventude rural como uma categoria construída sócio-historicamente, com características que variam de acordo com o local e as transformações que ocorrem no meio rural.

Lopes e Carvalho (2017), encontraram dentro do grupo pesquisado uma distinção entre os jovens e os "jovens mais jovens". Os primeiros construíram sua identidade na luta pela terra, por terem participado desse momento de conquista, os mais jovens têm construído essa identidade vinculada à terra a partir da educação contextualizada. Antes dessa educação, não tinham muito interesse pelas atividades cotidianas e tinham planos voltados para o espaço urbano; após, passaram a verem-se mais implicados nesse contexto de modo que muitos planejam sair para cursar o Ensino Superior e regressar para o assentamento para trazer benefícios. 
Há entre eles uma valorização do ambiente rural a partir das relações vivenciadas, a proximidade de todos, não só dos jovens. Apesar de serem vistos como os promotores de festas do assentamento, há um lugar político e de voz para os jovens. Lopes e Carvalho (2017) destacam a importância da Educação do Campo para os "mais jovens", que resulta em sua vinculação com a terra, por uma via diversa dos outros jovens, mas igualmente necessária para sua construção e permanência.

Viola (2019) traz uma discussão psicanalítica sobre conceito e objeto na obra de Lacan e uma hipótese sobre a concepção de adolescência na visão deste último. Viola concebe a adolescência como um momento em que há "a queda de certos véus que a infância até então proporciona ao sujeito", a puberdade conta "com a presença irreparável da falta" (VIOLA, 2019, p. 60). Ao fazer uma leitura de Lacan e seu encontro com a obra de Vygotsky, Viola (2019) conclui que a entrada no pensamento lógico, que ocorre na adolescência, "é uma forma de maturação que pode dar suporte ao sujeito nessa difícil transição (VIOLA, 2019, p. 60)", que se constitui como o desligamento da autoridade dos pais, a vivência das questões sexuais de forma inédita e da travessia ao Outro ${ }^{2}$ social.

\subsection{Encontros, divergências e alguns apontamentos}

Foi possível observar, nos textos analisados, variações na forma de lidar com as denominações de adolescência e juventude. Oliveira e Machado (2015), Gurski e Pereira (2016), Traverso-Yépez e Pinheiro (2005) e Teixeira (2014) não fazem diferença entre adolescência e juventude; Lopes e Carvalho (2017), Augusto (2005), Andrade e Meyer (2014) e Maheirie et al. (2013) utilizam apenas juventude; Viola (2019) e Bertol e Souza (2010) se referem somente à adolescência.

Trancoso e Oliveira (2014) trazem uma diferenciação entre os conceitos, destacando, porém, que há um momento em que se cruzam, no que se refere às faixas etárias. Coimbra, Bocco e Nascimento (2005, p. 7) preferem o uso do termo juventude, em substituição à adolescência, por entenderem que juventude traduz melhor "as forças que atravessam e constituem os sujeitos em vez das formas com que se tenta defini-los", já que consideram que o termo adolescente carrega consigo uma identidade fechada, com uma série de comportamentos reconhecidos como pertencentes a essa fase.

2 Termo cunhado por Lacan "para distinguir o que é da alçada do lugar terceiro, isto é, da determinação pelo inconsciente freudiano (Outro), do que é do campo da pura dualidade (outro) no sentido da psicologia" (ROUDINESCO; PLON, 1998, p. 558). 
Nos artigos selecionados, nota-se que não há uma preocupação em definir faixa etária para juventude ou adolescência. Embora haja, em alguns textos, uma citação quanto às questões legais, de modo geral, os autores discutem a adolescência e a juventude pela via de suas construções epistemológicas. Bertol e Souza (2010), Teixeira (2014), Oliveira e Machado (2015), Gurski e Pereira (2016) e Viola (2019) pautam suas discussões a partir da psicanálise; Traverso-Yépez e Pinheiro (2005), Coimbra, Bocco e Nascimento (2005), Augusto (2005), Andrade e Meyer (2014), Trancoso e Oliveira (2014) e Lopes e Carvalho (2017) partem de uma perspectiva sócio-histórica; Maheirie et al. (2013) não externam uma perspectiva própria por tratar-se de um artigo que busca trazer um panorama relativo a outras publicações.

Em sua maioria, os autores distanciam-se de uma visão naturalizante da adolescência, buscando trazer uma contextualização e discussão sobre estigmas, construção de identidade, papeis de gênero, questões sociais e políticas que rondam a adolescência e a juventude atual. Nota-se que esse distanciamento de uma visão puramente desenvolvimentista guarda algumas diferenças entre os estudos: os de ordem psicanalítica procuram promover um olhar mais individualizado para as diversas subjetividades e falam sobre os reflexos da vida atual para a construção do sujeito, enquanto as discussões de cunho sócio-histórico trazem uma visão mais crítica e voltada às questões sociais.

Embora sob perspectivas diferentes, os autores valorizam a adolescência e a juventude em si mesmas, não a colocam somente como uma fase passageira, mas uma construção humana que precisa ser considerada na sociedade contemporânea e que adquire diversas nuances a partir dos lugares e olhares.

Destaca-se a oportunidade de dar voz aos adolescentes e jovens para que falem sobre sua identidade, o modo como se percebem, como é o caso dos estudos de Traverso-Yépez e Pinheiro (2005), Andrade e Meyer (2014) e Lopes e Carvalho (2017), que discutem os conceitos de adolescência e juventude com os participantes de suas pesquisas e fazem apontamentos a partir de suas falas, demonstrando as variadas formas de construção de identidade e como o meio em que se vive é determinante para essas construções, bem como a importância dos questionamentos para não eternizar lugares comuns, como é o caso das questões de gênero.

Nos artigos puramente teóricos, sobressaem temas como a vivência do tempo, o excesso de informações, os estigmas da adolescência e a reflexão sobre a juventude nos dias atuais, que aparece como algo desejado e permanente, visto que as pessoas buscam cada vez mais a 
aparência jovem e certas características, como a vivência do prazer e da felicidade momentânea, em detrimento da experiência, que vai perdendo seu lugar.

O relato de experiência trazido por Teixeira (2014), embora focado no atendimento de uma adolescente, demonstra que as vulnerabilidades não são somente sociais e precisam ser consideradas quando se trata da adolescência, que é colocada pela autora como um momento de tornar-se sujeito e assumir certas responsabilidades.

Os artigos de Maheirie et al. (2013) e Trancoso e Oliveira (2014) contribuem com um panorama geral de várias obras que versam sobre a juventude e destacam a importância de discutir e questionar esse conceito na literatura, visto que ainda existem produções que, embora tratem dessas categorias, o fazem de forma acrítica, sem assumir uma conceituação.

\section{CONSIDERAÇÕES FINAIS}

Seja para falar em políticas públicas, formas de atenção ou ensino aos adolescentes e jovens, é importante questionar de que ponto de vista se está falando, qual a concepção de adolescência e juventude está sendo considerada, para que não se incorra no risco de percebêlos como rebeldes, transgressores ou outros estigmas que muitas vezes são a eles atrelados.

Algo relevante colocado pelos autores selecionados é a necessidade dos questionamentos, de não encerrar a adolescência e a juventude numa faixa etária, mas de considerar o contexto de cada um, as identidades neles forjadas, as subjetividades e as necessidades aí produzidas.

A visão puramente desenvolvimentista, onde a vida adulta é o objetivo maior a ser alcançado e a adolescência e a juventude se constituem como uma fase igual para todos e de caráter biológico é um apontamento colocado em xeque, visto que, até numa mesma pesquisa, em entrevistas com pessoas diferentes, é possível encontrar divergências quanto ao momento vivido, como é possível verificar nas pesquisas de campo de Traverso-Yépez e Pinheiro (2005), Andrade e Meyer (2014) e Lopes e Carvalho (2017) aqui descritas.

Não se trata de negar que existam encontros nos modos de ser adolescente ou jovem. A questão central é que não há uma universalidade, sequer um padrão onde todos se encaixem, mas é possível estabelecer práticas que sejam contextualizadas, que se pautem nas necessidades dos grupos a que se destinam.

Escutar as falas dos adolescentes e jovens a respeito de si mesmos é um caminho por onde se podem construir práticas voltadas a esse público que venham a trazer-lhes benefícios conforme as suas demandas. Portanto, algo que se pode inferir a partir dos estudos descritos, é 
que estudar a adolescência e a juventude, requer, além das construções teóricas (que são o norte de qualquer pesquisa e não podem ser prescindidas), um olhar específico para cada grupo, para cada meio e suas vivências.

\section{REFERÊNCIAS}

ANDRADE, Sandra; MEYER, Dagmar. Juventudes, moratória social e gênero: flutuações identitárias e(m) histórias narradas. Curitiba: Educar em Revista, edição especial, n. 1, p. 8599, 2014. Disponível em: https://www.scielo.br/pdf/er/nspe-1/a07.pdf. Acesso em: 01 jan 2021.

ABERASTURY, Arminda; KNOBEL, Mauricio. A adolescência normal: um enfoque psicanalítico. Porto Alegre: Artmed, 1981.

ARIÈS, Philippe. História social da criança e da família. Rio de Janeiro: Livros Técnicos e Científicos, 1981.

AUGUSTO, Maria Helena. Retomada de um legado intelectual: Marialice Foracchi e a sociologia da juventude. Tempo Social, v. 17, n. 2, p. 11-33, 2005. Disponível em: https://www.scielo.br/scielo.php?script=sci arttext\&pid=S0103-20702005000200002. Acesso em: 01 jan, 2021.

BERTOL, Carolina; SOUZA, Mériti. Transgressões e adolescência: individualismo, autonomia e representações identitárias. Psicologia: Ciência e Profissão, v. 30, n. 4, p. 824839, 2010. Disponível em: https://www.scielo.br/scielo.php?pid=S141498932010000400012\&script=sci_abstract\&tlng=pt. Acesso em: 01 jan, 2021.

BOCK, Ana. A adolescência como construção social: estudo sobre livros destinados a pais e educadores. Revista Semestral da Associação Brasileira de Psicologia Escolar e Educacional (ABRAPEE), v. 11, n. 1, p. 63-76, 2007. Disponível em: https://www.scielo.br/pdf/pee/v11n1/v11n1a07.pdf. Acesso em: 20 fev. 2021.

BOTELHO, Louise; CUNHA, Cristiano; MACEDO, Marcelo. O método da revisão integrativa nos estudos organizacionais. Revista Gestão e Sociedade, v. 5, n, 11, p. 121-136, 2011. Disponível em: https://www.gestaoesociedade.org/gestaoesociedade/article/view/1220/906. Acesso em: 20 fev. 2021.

BRASIL. Lei 11.129, de 30 de junho de 2005. Institui o Programa Nacional de Inclusão de Jovens - ProJovem; cria o Conselho Nacional da Juventude - CNJ e a Secretaria Nacional de Juventude; altera as Leis $\mathrm{n}^{\circ}$ s 10.683, de 28 de maio de 2003, e 10.429, de 24 de abril de 2002; e dá outras providências. Disponível em: http://www.planalto.gov.br/ccivil_03/_Ato20042006/2005/Lei/L11129.htm. Acesso em 28 dez. 2020.

BRASIL. Lei 8.069, de 13 de julho de 1990. Dispõe sobre o Estatuto da Criança e do Adolescente e dá outras providências. Disponível em: http://www.planalto.gov.br/ccivil_03/leis/18069.htm. Acesso em: 19 fev. 2021. 
BRASIL. Lei 12.852, de 5 de agosto de 2013. Institui o Estatuto da Juventude e dispõe sobre os direitos dos jovens, os princípios e diretrizes das políticas públicas de juventude e o Sistema Nacional de Juventude - SINAJUVE. Disponível em: http://www.planalto.gov.br/ccivil_03/_ato20112014/2013/lei/112852.htm\#: :text=LEI\%20N\%C2\%BA\%2012.852\%2C\%20DE\%205\%20DE \%20AGOSTO\%20DE\%202013.\&text=Institui \%20o\%20Estatuto\%20da\%20Juventude,Siste ma\%20Nacional\%20de\%20Juventude\%20\%2D\%20SINAJUVE. Acesso em: 19 fev. 2021.

COIMBRA, Cecília; BOCCO, Fernanda; NASCIMENTO, Maria Lívia. Subvertendo o conceito de adolescência. Arquivos Brasileiros de Psicologia, v. 57, n. 1, p. 2-11, 2005. Disponível em: http://pepsic.bvsalud.org/pdf/arbp/v57n1/v57n1a02.pdf. Acesso em: 01 jan. 2021.

DAYRELL, Juarez. O jovem como sujeito social. Revista Brasileira de Educação, n. 24, p. 40-52, 2003. Disponível em: https://www.scielo.br/pdf/rbedu/n24/n24a04.pdf. Acesso em: 20 fev. 2021.

FREITAS, Maria; ABRAMO, Helena; LEÓN, Oscar. Juventude e adolescência no Brasil: referências conceituais. São Paulo: Ação educativa, 2005. Disponível em: http://buscajuventude.ibict.br:8080/jspui/handle/192/212. Acesso em 21 abr. 2021.

GURSKI, Rose; PEREIRA, Marcelo. A experiência e o tempo na passagem da adolescência contemporânea. Revista de Psicologia USP, v. 27, n. 3, p. p. 429-440, 2016. Disponível em: https://www.scielo.br/pdf/pusp/v27n3/1678-5177-pusp-27-03-00429.pdf. Acesso em: 01 jan. 2021.

LOPES, Leandro; CARVALHO, Denis. Juventude assentada e a identidade vinculada à terra. Psicologia e Sociedade, v. 29, p. 1-10, 2017. Disponível em:

https://www.scielo.br/pdf/psoc/v29/1807-0310-psoc-29-e159034.pdf. Acesso em: 02 jan. 2021.

MAHEIRIE, Kátia; GROFF, Apoliana.; BUENO, Gabriel; MATTOS, Laura; SILVA, Dâmaris; MÜLLER, Flora. Concepções de juventude e política: Produção acadêmica em periódicos científicos brasileiros (2002 a 2011). Estudos de Psicologia, v. 18, n. 2, p. 335342, 2013. Disponível em: https://www.scielo.br/pdf/epsic/v18n2/v18n2a20.pdf. Acesso em: 02 jan. 2021.

MATHEUS, Thiago. Adolescência: conceito adolescente? Pulsional Revista de Psicanálise, n. 179, p. 26-32, 2004. Disponível em:

https://gvpesquisa.fgv.br/sites/gvpesquisa.fgv.br/files/arquivos/tiago c matheus adolescencia conceito adolescente.pdf. Acesso em: 01 jan. 2021.

NAVES, Flaviana. Interfaces entre a Psicologia Sócio-Histórica e a educação popular com adolescentes. Minas Gerais: Revista Interinstitucional de Psicologia, v. 9, n. 1, jan-jun, 2016, p. 32-49. Disponível em: http://pepsic.bvsalud.org/pdf/gerais/v9n1/v9n1a04.pdf. Acesso em 19 fev. 2021.

OLIVEIRA, Adriano; MACHADO, Márcia. A adolescência e a espetacularização da vida. Psicologia e Sociedade, v. 27, n. 3, p. 529-536, 2015. Disponível em: 
https://www.scielo.br/pdf/psoc/v27n3/1807-0310-psoc-27-03-00529.pdf. Acesso em: 02 jan. 2021.

PAIS, José. A construção sociológica da juventude: alguns contributos. Análise social, v. 25, p. 139-165, 1990. Disponível em:

http://analisesocial.ics.ul.pt/documentos/1223033657F3sBS8rp1Yj72MI3.pdf. Acesso em: 22 abr. 2021.

PERALVA, Angelina. O jovem como modelo cultural. Revista Brasileira de Educação, n. 6, p. 15-24, 1997. Disponível em:

http://anped.tempsite.ws/novo_portal/rbe/rbedigital/RBDE05_6/RBDE05_6_04_ANGELINA _PERALVA.pdf. Acesso em 19 fev. 2021.

ROTHER, Edna. Revisão sistemática x revisão narrativa. Acta Paulista de Enfermagem, v. 20, n. 2, abr.-jun. 2007. Disponível em: https://www.scielo.br/scielo.php?pid=S010321002007000200001\&script=sci_arttext\&tlng=pt. Acesso em: 22 abr. 2021.

ROUDINESCO, Elisabeth; PLON, Michel. Dicionário de Psicanálise. Rio de Janeiro: Zahar, 1998.

SHOEN-FERREIRA, Teresa; AZNAR-FARIAS, Maria; SILVARES, Edwiges. Adolescência através dos séculos. Psicologia: Teoria e Pesquisa, v. 26, n. 2, p. 227-234, 2010. Disponível em: https://www.scielo.br/pdf/ptp/v26n2/a04v26n2.pdf. Acesso em: 20 fev. 2021.

TEIXEIRA, Leônia. O sujeito adolescente e a intervenção psicanalítica: notas a partir de um caso clínico. São Paulo: Revista Latinoamericana de Psicopatologia Fundamental, v. 17, n. 3, p. 797-804, 2014. Disponível em: https://www.scielo.br/pdf/rlpf/v17n3s1/1415-4714rlpf-17-03-s1-00797.pdf. Acesso em: 02 jan. 2021.

TRANCOSO, Alcimar; OLIVEIRA, Adélia. Produção social, histórica e cultural do conceito de juventudes heterogêneas potencializa ações políticas. Psicologia e Sociedade, v. 26, n. 1, p. 137-147, 2014. Disponível em: https://www.scielo.br/pdf/psoc/v26n1/15.pdf. Acesso em: 01 jan. 2021.

TRAVERSO-YÉPEZ, Martha; PINHEIRO, Verônica. Socialização de gênero e adolescência. Florianópolis: Estudos Feministas, v. 13, n. 1, p. 147-162, 2005. Disponível em: https://www.scielo.br/pdf/ref/v13n1/a10v13n1.pdf. Acesso em 02 jan. 2021.

VIOLA, Daniela. A relação entre conceito e objeto na obra de Lacan e uma hipótese sobre a adolescência. Rio de Janeiro: Revista Ágora, v. 23, n. 1, p. 51-62, 2019. Disponível em: https://www.scielo.br/pdf/agora/v22n1/1809-4414-agora-22-01-51.pdf. Acesso em: 01 jan. 2021. 